\title{
Water Related Properties to Assess Soil Quality in Two Olive Orchards of South Spain under Different Management Strategies
}

\author{
Gema Guzmán ${ }^{1}\left(\mathbb{D}\right.$, Alberto-Jesus Perea-Moreno ${ }^{1, *(\mathbb{C})}$, José Alfonso Gómez ${ }^{2}$, \\ Miguel Ángel Cabrerizo-Morales ${ }^{3}$, , Gonzalo Martínez ${ }^{1}\left(\mathbb{D}\right.$ and Juan Vicente Giráldez ${ }^{4}$ \\ 1 Departamento de Física Aplicada, Universidad de Córdoba, 14071 Córdoba, Spain; g92gudim@uco.es (G.G.); \\ gonzalo.martinez@uco.es (G.M.) \\ 2 Instituto de Agricultura Sostenible-CSIC, 14080 Córdoba, Spain; joseagomez@ias.csic.es \\ 3 Producciones Científicas y Técnicas, Universidad de Granada, 18150 Granada, Spain; \\ macabrerizo@gmail.com \\ 4 Departamento de Agronomía, Universidad de Córdoba, 14071 Córdoba, Spain; ag1gicej@uco.es \\ * Correspondence: aperea@uco.es; Tel.: +34-957-212-633
}

Received: 29 December 2018; Accepted: 18 February 2019; Published: 21 February 2019

\begin{abstract}
Soil quality is usually assessed through the measurement of selected soil properties. However, in spite of the diversity of the chosen properties, use of the soil water retention curve, like the pressure head or the specific water capacity at the inflection point, provides relevant information of degradation or improvement of soil. The main aim of this study was to evaluate the methods based on these indices in the evaluation of short-term changes of olive cropped soils under typical Mediterranean agricultural conditions. For this reason, soil properties (bulk density, hydraulic conductivity, aggregates stability, and organic matter content) were measured in a short-term trial settled in two olive orchards under different soil managements: tillage and cover crop. Several sampling areas were also distinguished: (i) along the inter tree row and under the canopies' projection and (ii) at 0-10 cm and 10-20 cm depth. In addition, water retention curves were determined and fitted using two models (van Genutchen's and Kosugi's) in order to obtain the inflection point and therefore the $S$ index. This index is the maximum value of the slope of the soil water retention curve and is related to soil quality. At the two sites, changes in soil management, even after a brief period of two years, had a relatively quick effect, especially in organic matter content along the inter tree row. The use of indices based on soil water retention curves helps to detect soil degradation or improvement changes. Future research, including the inclusion of more soil types and longer time periods, might lead to the development of more refined tools for the assessment of soil health.
\end{abstract}

Keywords: olive orchard; water retention curve; $S$ index; soil management; soil health

\section{Introduction}

Soil erosion is a severe environmental threat for the future of our society [1], especially on steep slopes and under a Mediterranean climate where the rainy season starts after a hot and dry summer season without a protective plant cover [2]. It is precisely in those areas where an important part of traditional olive groves is located. Andalusia, in southern Spain, is the first oil-producing region of the world. In the region, about $25 \%$ of the olive orchards grow on steep terrain with average slopes of over $20 \%$, while another $59 \%$ of the area is cultivated in slopes ranging between $5 \%$ and $20 \%$. Therefore, the food supply and conservation of the Earth pose a challenge for the society; in the words of Sposito [3], to sustain the "genius of soil", which means the optimization of the natural resources like the soil, respecting the complexity of its ecosystem. 
Among other entities, the European Union [4] considers the establishments of cover crops and residue management as two useful management practices to the mentioned optimization of natural resources. Cover crops can enhance $\mathrm{C}$ sequestration and $\mathrm{N}$ retention, as well as improve the stability of soil aggregates and other physical characteristics [5,6], which are two of the three essential properties of soil indicated by Palm et al. [7]: Texture, mineralogy, and soil organic carbon. The other soil properties are dependent on these basic ones. Nevertheless, any soil management system requires an evaluation index to assess its efficiency [8].

Considering the soil's physical quality, the soil water retention curve (SWRC) is possibly the most relevant property, given that many other characteristics are derived or related to it. Since the matric component of the soil water potential—or its absolute value, the pressure head—can be expressed as a function of the pore radius, the Young-Laplace equation [9], the SWRC is, essentially, the probability distribution function of the effective pore radius of the soil [10]. Soil pores are usually separated according to their estimated size. The greater pores, meso- and macropores, whose radii are greater than $30 \mu \mathrm{m}$, [11], are often denominated as structural pores and very conveniently transfer water within the soil. On the contrary, in the smaller pores, micropores, or textural pores, water moves very slowly. Therefore, soil quality is linked to the abundance of meso and macropores. Nevertheless, there is not a clear threshold to clearly delimit the fraction of great pores. One possible choice for the definition of an index of soil quality is the maximum value of the slope of the soil water retention curve, the derivative of water content with respect to the pressure head, the water capacity, specific water capacity [12], or the inflection point of the soil water retention function. Early in the nineteen-forties, Childs [13] proposed a stability index for soil structure based on the mode of the pore size distribution of the soil, defined as the value of the maximum specific water capacity, corrected by a baseline connecting the two neighbor local minima. The method, known as the high energy moisture curve HEMC, was refined by replacing the corrected mode with an averaged value [14] called the structural index. The ratio between the structural indexes of two soil water retention curves measured under slow and fast wetting processes was defined as the stability ratio. This method is widely used to assess the structure changes of soil [15].

Use of the inflection point of the soil water retention curve for the design of the stability index has been adopted for different purposes. Dexter [16-18] formulated a soil quality index, the $S$ index, which is the slope of the soil water retention curve at the inflection point, when the pressure head is replaced by its natural logarithm. Therefore, the $S$ index is a new version of the maximum value of the specific water capacity, similar to the stability index of Childs. This index has been shown to be related to some agronomic and edaphic characteristics suggested for the evaluation of soil quality [19-21]. Assouline and Or [22] choose the tangent to the soil water retention curve at the inflection point to estimate the water content and the pressure head at the state of field capacity. The intersection of the tangent with the pressure head axis defined the value of the field capacity, and the corresponding water content was found in the soil water retention curve. Han et al. [23] improved the estimation of the saturated hydraulic conductivity of soils with inclusion of the inflection point parameters. Therefore, the inflection point of the soil water retention curve, or the slope of its tangent at such a point, can be adopted to evaluate the physical soil quality.

The purpose of this report is the exploration of the indices of soil quality for the assessment of conservation practices like the cover crops applicable to extensive rainfed tree crops of Mediterranean areas. The main objectives are (i) to develop and evaluate the SWRC inflection point-based methods to assess soil physical quality of the olive orchards soils, (ii) to assess the short-term changes (2 years) in soil water flow and chemical properties in two olive orchards under different soil managements, conventional tillage, and cover crop, and (iii) to propose some strategies for assessing the quality of soil in olive orchards based on the results. 


\section{Materials and Methods}

\subsection{Studied Area}

The experimental trials were carried out in two representative olive orchard farms with different soil characteristics. The first one was called Pedrera, the name of the closest village, and was located in the southeast of Seville province (Spain), $37^{\circ} 13^{\prime} \mathrm{N} ; 4^{\circ} 53^{\prime} \mathrm{W}$. It is a rainfed olive orchard that was planted in 1999 with a frame of $6 \times 7 \mathrm{~m}^{2}$ with the variety "Hojiblanca". Test plots were established in an area with an average slope of $4 \%$. The soil, a clay loam, belongs to subgroup Typic Calcixerept [24]. It is a well-drained soil with abundant stoniness, about $36 \%$ of carbonate content, with low organic matter content at $1.6 \%$. The climate of the area is Mediterranean, Csa, within the Köppen-Geiger climate classification [25], temperate with dry and hot summers. The mean annual temperature is $18{ }^{\circ} \mathrm{C}$ and it has an annual rainfall of $550 \mathrm{~mm}$. The second farm, called Benacazón, is the neighboring village, and is located west from the capital of the Seville province (Spain), $37^{\circ} 21^{\prime} \mathrm{N} ; 6^{\circ} 11^{\prime} \mathrm{W}$, in a small spur of reduced elevation roughly parallel to the Guadalquivir river course. It is an irrigated farm of green table olives planted with the variety "Gordal" in 1980 in a frame of $8 \times 7 \mathrm{~m}^{2}$. Test plots were established on an average slope of $11 \%$. The soil, a sandy loam, belongs to the subgroup Petrocalcic Palexeralf [24]. It is a well-drained soil, with no appreciable stoniness, an average content of $1.3 \%$ organic matter, and $28 \%$ of carbonate content. The climate is Mediterranean, similar to the other farm, Csa, with a mean annual temperature of $18.6^{\circ} \mathrm{C}$ and annual precipitation of $534 \mathrm{~mm}$ [26].

In both farms, two runoff plots parallel to the maximum slope gradient were installed using collector tanks connected by primers. Two different soil management systems were chosen (one per plot). In Pedrera, settled in May 2002, were $12 \times 65 \mathrm{~m}^{2}$, while in Benacazón, installed in June 2003, the plots' dimensions were $8 \times 60 \mathrm{~m}^{2}$. One management system was conventional tillage (hereafter referred as tillage) consisting of weeds control by 2-4 cultivator passes at a depth of $15 \mathrm{~cm}$. The number of passes per year varied depending on weather conditions and, therefore, growth of adventitious vegetation. The usual distribution is one pass at the beginning of the year (after harvesting in autumn), followed by several passes (between one and three) at the end of winter and spring.

The second soil management system was temporary cover crop, hereafter called cover. This management system consisted of a sown cover crop of ryegrass (Lolium multiflorum) along the inter tree rows every year, with the first autumn rains. The cover was sown by hand at a seed density of $40 \mathrm{~kg} \mathrm{ha}^{-1}$ and fertilized during the winter with 14-14-16 at a dose of $270 \mathrm{~kg} \mathrm{ha}^{-1}$. In early spring (between mid-March and mid-April) depending on annual rainfall, the cover was chemically killed with paraquat $12 \%$ + diquat $8 \%$ to avoid water and nutrient competition with the olive trees according to the local mowing date recommendations [27].

These two managements were set up in Pedrera and Benacazón before closing the runoff plots. Thus, soil management began in fall 2001 and spring 2003, respectively. The previous soil management systems in the whole farms were conventional tillage in Pedrera and spontaneous cover in Benacazón.

\subsection{Field Measurements}

Field measurements and soil sampling for laboratory analysis were performed during January and April 2005 along the inter tree rows (X) and under olive trees' canopies (C) at two different depths, 0-10 cm (S) and 10-20 cm (P). In the case of the tillage plots, measurements and sampling coincided when soil compaction was maximum, just before the first plough pass in early spring. 
Selected soil chemical and physical properties were measured: organic matter (OM), bulk density (BD), saturated hydraulic conductivity (Ks), and macroaggregate stability (AE). In addition, water retention curves (WRC) were determined in undisturbed soil samples (samples in $50 \times 50 \mathrm{~mm}^{2}$ cores) during a drying cycle using a sand box and a sand/kaolin box for $\mathrm{pF}$ determination (Eijkelkamp Giesbeek, The Netherlands), which range to $1 \mathrm{wcm}$ and from 1 to $5 \mathrm{wcm}$, respectively. For lower water potentials of higher than $5 \mathrm{wcm}$ of suction, disturbed soil samples were analyzed using a dewpoint potentiameter (WP4C, Decagon, Pullman, WA, USA). The number of samples taken, or measurements per management, area, and depth was eight for $\mathrm{BD}, \mathrm{AE}$, and $\mathrm{WRC}$, and four for the rest of the parameters. Detailed information about the protocols can be found in [28].

\subsection{Water Retention Curves and S Index}

The soil water retention curve has been characterized by several equations, what Raats denominated subclasses of a van Genuchten type $[29,30]$ relating the saturation degree, $S_{e}$, a normalized moisture content, $\theta$, using the maximum, $\theta_{0}$, and minimum value, $\theta_{r}$

$$
S_{e}=\frac{\theta-\theta_{r}}{\theta_{0}-\theta_{r}}
$$

with the pressure head, $h$, normalized with the parameter $\alpha$, using some auxiliary parameters $n$ and $m$. The water retention equation is

$$
S_{e}=\left[1+(\alpha h)^{n}\right]^{-m}
$$

The value of the pressure head at the inflection point of the soil water retention curve, $h_{I P}$, is

$$
h_{I P}=\alpha\left(\frac{1-n^{-1}}{m+n^{-1}}\right)^{1 / n}
$$

Finally, the value of the Dexter $S$ index is

$$
S=-n\left(1+m^{-1}\right)^{-(m+1)}
$$

Even though the two indices $h_{I P}$ and $S$ are basically similar, use of the logarithmic transformation in the pressure head implies some changes in their respective final equations. Inclusion of the logarithmic transformation could not be justified in some cases [31], but in this report it is kept.

In some soils, the simplest Brutsaert equation [32], a particular case of the van Genuchten subclass with $m=1$, fits very well the experimental data of the water retention curve. Another possible alternative is the Kosugi equation [33] based on the lognormal probability distribution function with three parameters [34], the pressure head at the inflection point, $h_{0}$, the pressure head at the air-entry state, $h_{c}$, and the shape parameter $\sigma$, for the pressure heads greater than the air-entry value, using the complementary of the error function, $\operatorname{erfc}$ [35]:

$$
S_{e}=2^{-1} \operatorname{erfc}\left\{\left(\sigma 2^{1 / 2}\right)^{-1}\left[\ln \left(\frac{h-h_{c}}{h_{0}-h_{c}}\right)-\sigma^{2}\right]\right\}
$$


In this equation the value of the Dexter $S$ index is with $\Delta \theta=\theta_{0}-\theta_{r}$

$$
S=(2 \pi)^{-1 / 2} \frac{\Delta \theta}{\sigma\left(1-h_{c} / h_{0}\right)} \exp ^{\left[-\frac{1}{2}\left(\frac{h_{c}}{\sigma h_{0}}\right)^{2}\right]}
$$

The two soil water retention equations were fitted to the measured data using the Rosenbrock optimization algorithm [36] by minimization with constraints of the sum of the squares of the differences between measured and computed values as the objective function.

\subsection{Statistical Analysis}

Basic statistical analysis (ANOVA and mean comparisons with a Tukey significance level of $p<0.05$ ) were carried out to evaluate the possible differences on soil properties regarding management (tillage, cover), areas (inter tree row, under canopies), and depths $(0-10 \mathrm{~cm}, 10-20 \mathrm{~cm})$. The data was analyzed using Statistix software v.8.1 (Analytical Software, Tallahassee, FL, USA).

\section{Results and Discussion}

\subsection{Field Measurements}

Table 1 shows a summary of the soil properties measured at the two farms (Pedrera and Bencazón), managements (tillage or cover), depths $(0-10 \mathrm{~cm}$ or $10-20 \mathrm{~cm}$ ) and areas (inter tree row or under canopies).

At the Pedrera farm, OM was slightly greater in the cover plot than in the tillage one, especially along the inter tree row, which denotes a quick response of the soil to the establishment of the cover. On the contrary, areas and depths presented similar content. BD was significantly different in all cases (managements, areas and depths) with the highest values at the top soil $(0-10 \mathrm{~cm})$ of the inter tree row of the tilled plot, due to the sampling date, before the first tillage pass. Differences in AE were detected regarding depths, denoting that an interaction between managements and areas exists.

At Benacazón site, the OM was significantly different between the soil management systems. The tilled plot showed in general terms greater values than the cover plot, suggesting the short-term effects of tillage in a plot subject to a traditional system, which included a spontaneous cover crop. These effects can be attributed to the homogenization of the profile by mixing different soil layers. Clear differences between areas were noticed, due to the small BD measured under the canopies in all cases. Some interactions between depths and areas were observed.

Concerning the Ks, Pedrera plots showed lower values than Benacazón due to differences in the clay content at both sites. Moreover, this property presented a great variability due to the occasional appearance of surface cracks during the infiltration tests at Pedrera. However, the highest values were found under the canopies, possibly due to the presence of olive tree roots and the associated porosity. 
Table 1. Average values and standard deviation (in brackets) at the two sites (Pedrera and Benacazón) and managements (tillage and cover) for the different areas: SX (0-10 cm inter tree row), PX (10-20 cm inter tree row), SC (0-10 cm under tree canopies) and PC (10-20 cm under tree canopies). Soil properties are bulk density (BD), saturated hydraulic conductivity (Ks), macroaggregate stability (AE) and organic matter (OM).

\begin{tabular}{|c|c|c|c|c|c|c|c|c|c|}
\hline \multirow{2}{*}{ Site } & \multirow{2}{*}{ Property } & \multicolumn{4}{|c|}{ Tillage } & \multicolumn{4}{|c|}{ Cover } \\
\hline & & SX & SC & PX & PC & SX & SC & PX & PC \\
\hline \multirow{4}{*}{ Pedrera } & $\mathrm{BD}\left(\mathrm{Mg} / \mathrm{m}^{3}\right)$ & $1.53(0.12)$ & $1.49(0.13)$ & $1.74(0.05)$ & $1.73(0.05)$ & $1.56(0.12)$ & $1.29(0.13)$ & $1.73(0.03)$ & $1.68(0.10)$ \\
\hline & $\mathrm{Ks}(\mathrm{mm} / \mathrm{h})$ & $2.9(5.2)$ & $6.1(5.6)$ & $3.4(6.6)$ & $3.4(1.2)$ & $3.3(1.1)$ & $8.5(1.7)$ & $8.7(8.6)$ & $17.2(17.2)$ \\
\hline & $\mathrm{AE}(\mathrm{kg} / \mathrm{kg})$ & $0.423(0.054)$ & $0.408(0.024)$ & $0.357(0.108)$ & $0.384(0.029)$ & $0.413(0.067)$ & $0.387(0.042)$ & $0.404(0.036)$ & $0.336(0.031)$ \\
\hline & $\mathrm{OM}(\%)$ & $1.6(0.1)$ & $1.7(0.3)$ & $1.4(0.2)$ & $1.4(0.2)$ & $2.3(0.4)$ & $1.9(0.2)$ & $1.5(0.1)$ & $1.4(0.4)$ \\
\hline \multirow{4}{*}{ Benacazón } & $\mathrm{BD}\left(\mathrm{Mg} / \mathrm{m}^{3}\right)$ & $1.44(0.08)$ & $1.23(0.05)$ & $1.56(0.08)$ & $1.40(0.08)$ & $1.68(0.28)$ & $1.30(0.05)$ & $1.46(0.08)$ & $1.29(0.05)$ \\
\hline & $\mathrm{Ks}(\mathrm{mm} / \mathrm{h})$ & $11.8(18.9)$ & 38.7 (19.9) & $33.5(14.9)$ & $27.3(24.0)$ & $11.8(6.9)$ & $32.0(22.9)$ & $39.6(12.6)$ & $37.0(17.9)$ \\
\hline & $\mathrm{AE}(\mathrm{kg} / \mathrm{kg})$ & $0.152(0.103)$ & $0.273(0.084)$ & $0.286(0.091)$ & $0.238(0.066)$ & $0.232(0.070)$ & $0.248(0.052)$ & $0.278(0.046)$ & $0.234(0.077)$ \\
\hline & $\mathrm{OM}(\%)$ & $1.6(0.5)$ & $1.8(0.4)$ & $1.0(0.4)$ & $1.9(0.5)$ & $1.3(0.4)$ & $1.1(0.2)$ & $0.8(0.1)$ & $1.6(0.3)$ \\
\hline
\end{tabular}




\subsection{Soil Quality and S Index}

The mode of the effective pore radius of the different treatments, the ordinate of the inflection point in the fitted soil water retention curves, are depicted in the box and whiskers plots of Figure 1. The data of this figure were estimated with the Kosugi water retention curve, whose results were similar to those computed with the van Genuchten equation, except for some soil samples of the Pedrera farm, whose retention curve did not show a clear air entry state. This property, also found in the SWRC of swelling soils of the zone [37], posed some problems to other authors [38]; Pierson and Mulla [13] suggested the addition of a second-degree polynomial to the van Genuchten water retention equation.

In any case, the plots of Figure 1 indicate the benefit of the cover crop treatment, which increased the range of greater effective pore volume fraction, as compared to the analog volume fraction of the tilled plot soils. This advantage is not as clear for the data of Benacazón farm. At this site, Benacazón, the plots of the subsoil, depth interval 10-20 cm, of the tilled and cover treatment of the soil samples collected under the canopy and in the alley between the tree lines, are greater than the corresponding values of the surface layer, $0-10 \mathrm{~cm}$, revealing alleviation of the compaction caused by the former cover crop in the soil layers by surface tillage in one case and by the root development in the other one. The observed differences of the mean values of samples collected under the canopy and in the inter tree area suggest the localized compaction of the olive fruit harvesting operation where the workers stand by the tree milking the lower branches bearing the fruits.
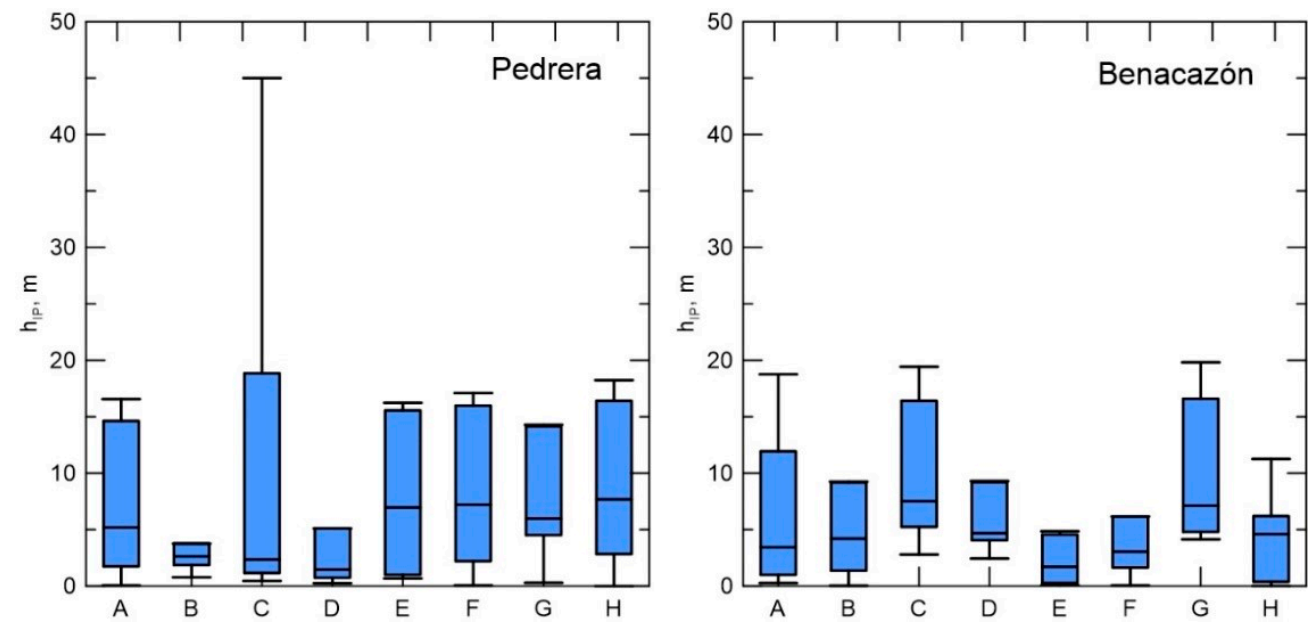

Figure 1. Box and whiskers plot showing the potential at the inflexion point from the WRC (Y axis) for the different management and areas at the two sites: Tillage: A $(0-10 \mathrm{~cm}$ inter tree row); B $(0-10 \mathrm{~cm}$ under tree canopies); C (10-20 cm inter tree row); D (10-20 cm under tree canopies) and Cover: $\mathrm{E}$ (0-10 cm inter tree row); F (0-10 cm under tree canopies); G (10-20 cm inter tree row); H (10-20 cm under tree canopies). The endings of each box indicate the inter-quartile range times 1.5. The box is defined by the lower and upper quartiles and the line in its center is the median.

Figure 2 shows the $S$ index obtained with the mean WRC of Pedrera (X axis) and Benacazón ( $Y$ axis). As Dexter [16-18] indicated, $S$ indexes over 0.035 are usually found in non-degraded soils. These results confirm the good quality of soils at both sites, and, in particular, Benacazón detected by farmers and agronomists.

However, it is worthy to comment the $S$ index values of the SX plots $(0-10 \mathrm{~cm}$ along the inter tree row). In Pedrera $(S=0.041)$, the beneficial effects of the cover can be clearly appreciated even in the brief period of implementation. On the other hand, in Benacazón the relatively small value of the $S$ index, $(S=0.031)$ could be attributed to the change from a spontaneous cover with autochthonous vegetation to a sown, monovarietal cover of a gramineous. 


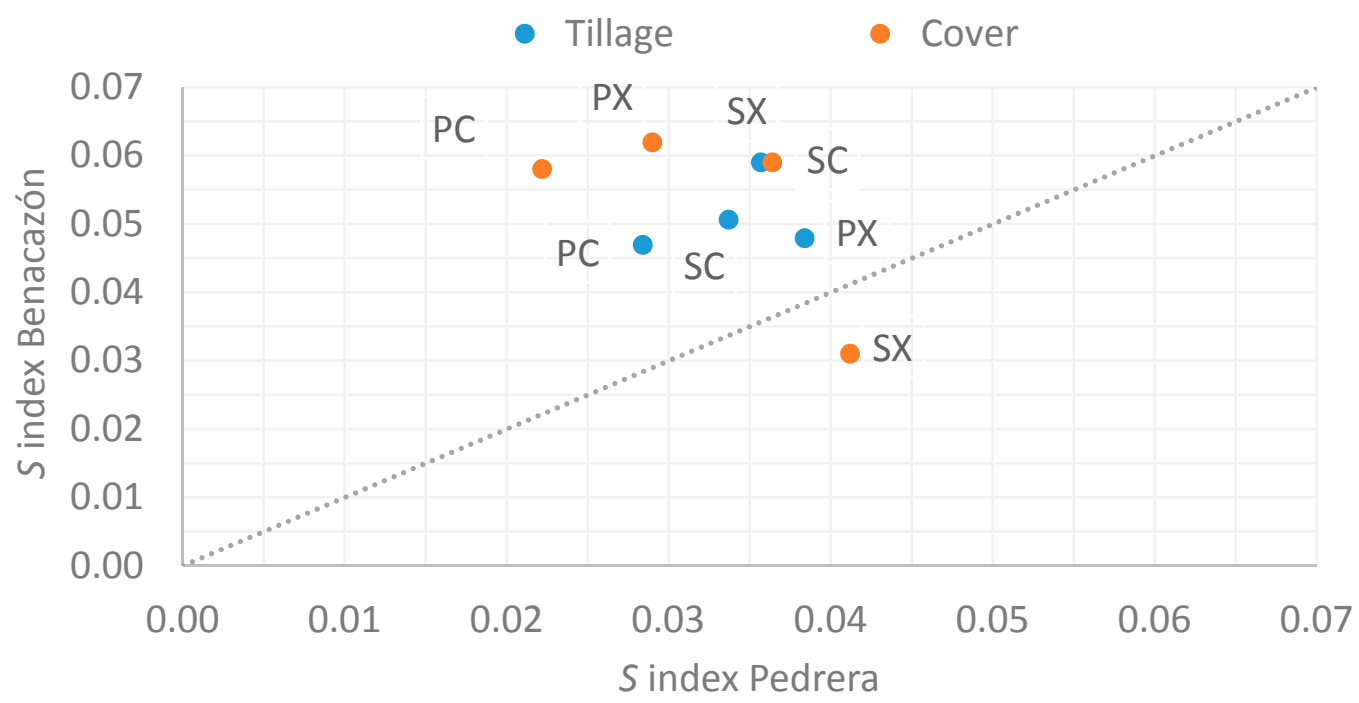

Figure 2. Comparison between the $S$ index at Pedrera ( $\mathrm{X}$ axis) and Benacazón ( $\mathrm{Y}$ axis) obtained with the mean WRC from the van Genutchen equation. Blue and orange dots show Tillage and Cover managements, respectively, at the different areas: SX (0-10 cm inter tree row), PX (10-20 cm inter tree row), SC (0-10 cm under tree canopies) and PC (10-20 cm under tree canopies).

Comparing the $S$ index values from the average WRC with some of the mean measured soil properties, no clear trend is evident; Figure 3. The lack of significant correlation might be the result of the confluence of several factors, such as the spatial variability of the measured properties, and the interaction among management systems, areas, and depths. Futhermore, for most of the cases, a change in the management systems was not always reflected by a significant variation of soil properties or $S$ index values. As was previously discussed, this effect was clearer at SX at both sites, which can be explained due to the fact that top soil at the inter tree rows is the most influenced zone within the two managements. 


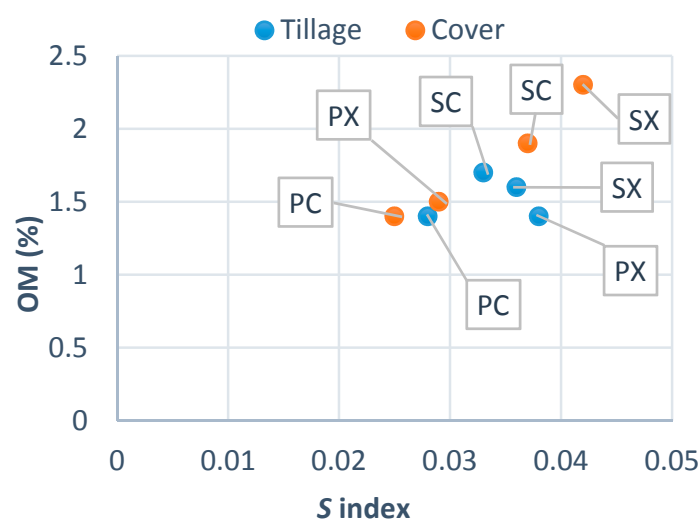

(a)

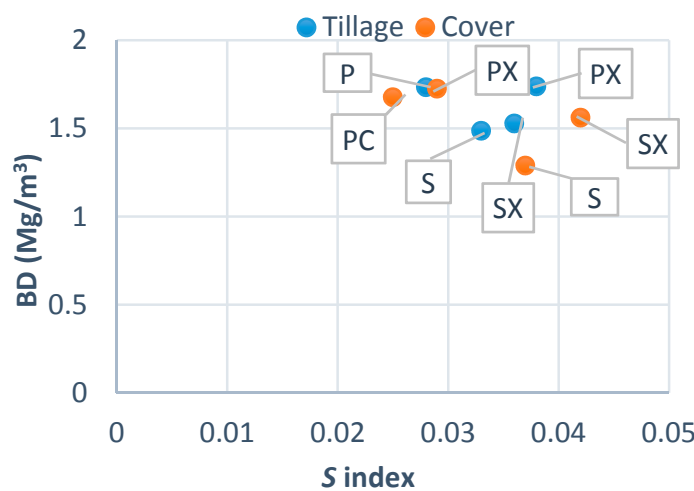

(c)

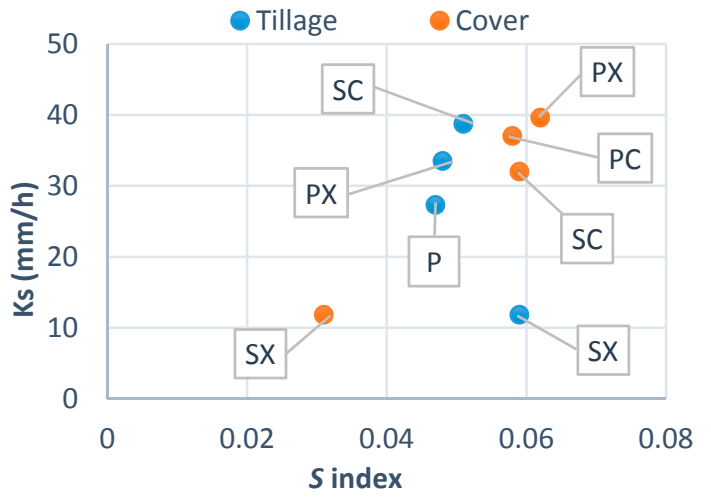

(e)

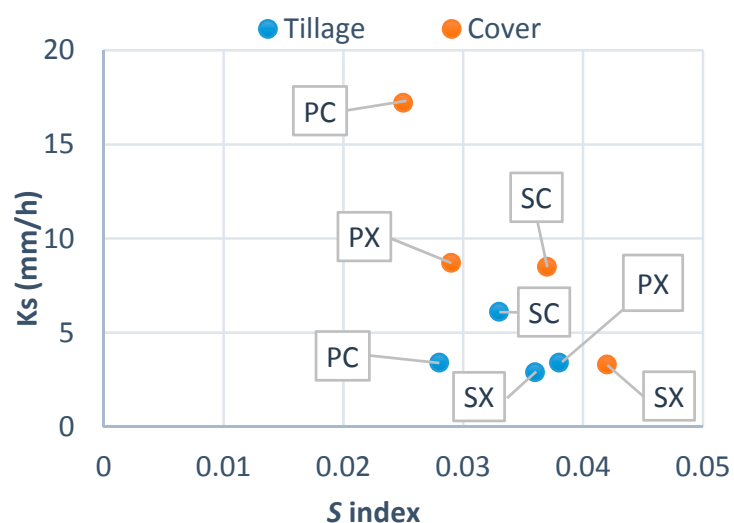

(b)

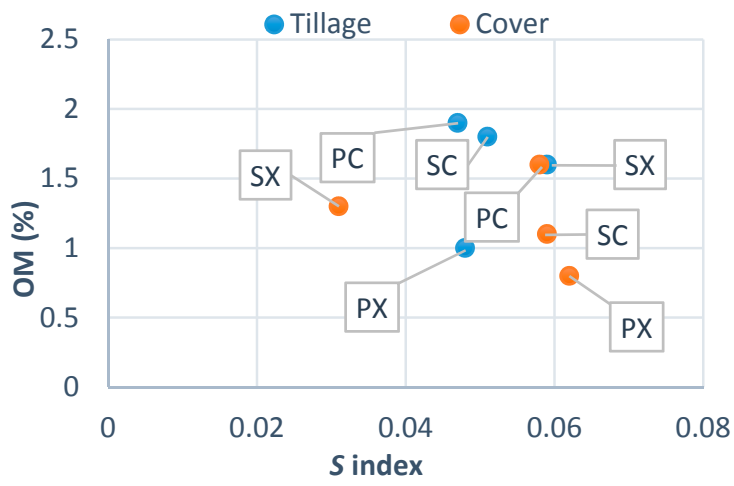

(d)

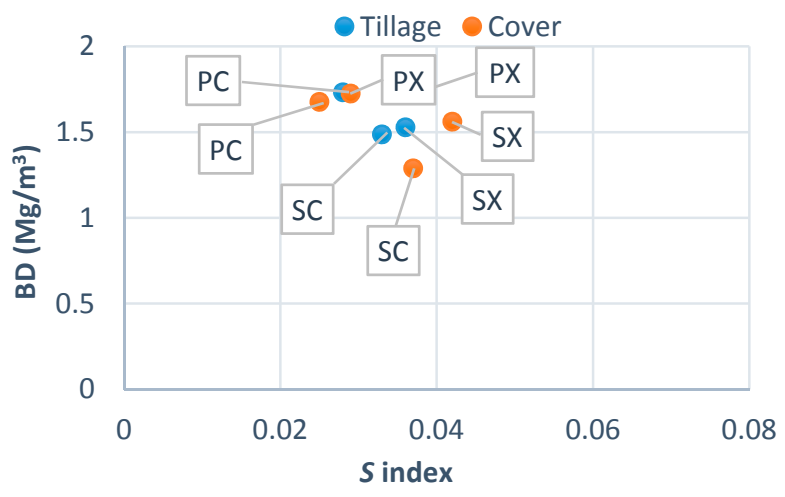

(f)

Figure 3. Comparison between the $S$ index obtained with the mean WRC from the van Genutchen approach ( $\mathrm{X}$ axis) and selected soil properties ( $\mathrm{Y}$ axis): organic matter $(\mathrm{OM})$, saturated hydraulic conductivity (Ks) and bulk density (BD) at Pedrera (a-c) and Bencazón (d-f). Blue and orange dots show Tillage and Cover managements, respectively, at the different areas: SX (0-10 cm inter tree row), PX (10-20 cm inter tree row), SC (0-10 cm under tree canopies) and PC (10-20 cm under tree canopies)

These results suggest that application of the $S$ index for the evaluation of soil quality in Mediterranean soils of woody plantations, such as olive groves, does not seem free of uncertainties. They also indicate the need of more detailed research (e.g., including a larger set of soil properties and expanding the temporal scale) to address whether the aspects discussed in this study, such as the lack of correlation of the $S$ indexes derived from different models, can be satisfactorily resolved for their application in soil characterization and evaluation. In any case, it is remarkable that such a simple index can describe relevant physical properties of the soil. 


\section{Conclusions}

The two soils studied showed how the change of soil management, from cover to tillage in Benacazón, or the reverse, from tillage to cover, in Pedrera, have generated a relatively rapid change of some soil properties. This suggests that, for the studied soils, soil degradation processes associated with tillage or with a simplified cover crop occur relatively quickly (Benacazón), but they demonstrate also that the improvement of soil properties associated with the introduction of a cover crop (Pedrera) follows the same trend. Future work expanding the number of soils studied and measuring the evolution of soil properties over a longer time interval should improve these preliminary results.

The observed correlation between the stability of macro-aggregates in water, a classical indicator, and some porosity characteristics of soils, detected by both indices of soil quality, recommends their adoption in future studies of soil health.

Given the limited nature of the dataset, our results suggest the usefulness of the inclusion of this combined approach in future studies due to the relative simplicity of field and laboratory work involved in the determination of selected properties and WRCs. Deeper research advances must be carried out to fully assess its potential with evaluating soil degradation due to different agricultural managements in Mediterranean areas.

Author Contributions: G.G. and J.A.G. dealt with the data acquisition, modelling and writing. A.-J.P.-M., G.M. and M.Á.C.-M. collaborated with the literature review, analysis of the data, writing and editing the text. J.V.G. participated in the literature review, modelling of the data and writing.

Funding: This work was supported by project P12-AGR-931 (Andalusian Government), projects ProTerra I-II and Biosuelo (Syngenta) and EU-FEDER funds.

Acknowledgments: The authors would like to thank the Editor and the anonymous reviewers for their comments and contributions to the manuscript.

Conflicts of Interest: The authors declare no conflict of interest.

\section{References}

1. Amundson, R.; Berhe, A.A.; Hopmans, J.W.; Olson, C.; Sztein, A.E.; Sparks, D.L. Soil and human security in the 21st century. Science 2015, 348. [CrossRef] [PubMed]

2. Soriano, M.-A.; Álvarez, S.; Landa, B.B.; Gómez, J.A. Soil properties in organic olive orchards following different weed management in a rolling landscape of Andalusia, Spain. Renew. Agric. Food Syst. 2014, 29, 83-91. [CrossRef]

3. Sposito, G. Sustaining "The genius of soils". In The Soil Underfoot: Infinite Possibilities for a Finite Resource; Churchman, G.J., Landa, E.R., Eds.; Taylor and Francis: Boca Raton, FL, USA, 2014.

4. Ten Berge, H.F.M.; Schröder, J.J.; Olesen, J.E.; Giráldez, J.V. Research for AGRI Committee-Preserving Agricultural Soils in the EU; European Parliament, Policy Dept. for Structural and Cohesion Policies: Brussels, Belgium, 2017.

5. García-González, I.; Hontoria, C.; Gabriel, J.L.; Alonso-Ayuso, M.; Quemada, M. Cover crops to mitigate soil degradation and enhance soil functionality in irrigated land. Geoderma 2018, 322, 81-88. [CrossRef]

6. Palese, A.M.; Vignozzi, N.; Celano, G.; Agnelli, A.E.; Pagliai, M.; Xiloyannis, C. Influence of soil management on soil physical characteristics and water storage in a mature rainfed olive orchard. Soil Tillage Res. 2014, 144, 96-109. [CrossRef]

7. Palm, C.; Sánchez, P.; Ahamede, S.; Awiti, A. Soils: A contemporary perspective. Ann. Rev. Environ. Res. 2007, 32, 99-129. [CrossRef]

8. Karlen, D.L.; Mausbach, M.J.; Doran, J.W.; Cline, R.G.; Harris, R.F.; Schuman, G.E. Soil quality: A concept, definition, and framework for evaluation. Soil Sci. Soc. Am. J. 1997, 61, 4-10. [CrossRef]

9. Warrick, A.W. Soil Water Dynamics; Oxford Univ. Press: Oxford, UK, 2003.

10. Or, D.; Tuller, M. Liquid retention and interfacial area in variably saturated porous media: Upscaling from single-pore to sample-scale model. Water Resour. Res. 1999, 35, 3591-3605. [CrossRef]

11. Brewer, R. Fabric and Mineral Analysis of Soils; John Wiley and Sons: New York, NJ, USA, 1964.

12. Childs, E.C. The use of soil moisture characteristics in soil studies. Soil Sci. 1940, 50, 239-252. [CrossRef] 
13. Pierson, F.B.; Mulla, D.J. An improved method for measuring aggregate stability of a weakly aggregated loessial soil. Soil Sci. Soc. Am. J. 1989, 53, 1825-1831. [CrossRef]

14. Collis-George, N.; Figueroa, B.S. The use of high energy moisture characteristic to assess soil stability. Aust. J. Soil Res. 1984, 22, 349-356. [CrossRef]

15. Mamedov, A.I.; Levy, G.J. High energy moisture characteristics: Linking between some physical processes and structure stability. In Quantifying and Modeling Soil Structure Dynamics; Logsdon, S., Berli, M., Horn, R., Eds.; Soil Science Society of America, Inc.: Madison, WI, USA, 2013; Volume 3.

16. Dexter, A.R. Soil physical quality: Part I. Theory, effects of soil texture, density, and organic matter, and effects on root growth. Geoderma 2014, 120, 201-214. [CrossRef]

17. Dexter, A.R. Soil physical quality: Part II. Friability, tillage, tilth and hardsetting. Geoderma 2004, 120, $215-225$. [CrossRef]

18. Dexter, A.R. Soil physical quality: Part III. Unsaturated hydraulic conductivity and general conclusions about S-theory. Geoderma 2004, 120, 227-239. [CrossRef]

19. Pulido-Moncada, M.; Ball, B.C.; Gabriels, D.; Lobo, D.; Cornelis, W.M. Evaluation of soil physical quality index s for some tropical and temperate medium-textured soils. Soil Sci. Soc. Am. J. 2014, 79, 9-19. [CrossRef]

20. Armindo, R.A.; Wendroth, O. Physical soil structure evaluation based on hydraulic energy functions. Soil Sci. Soc. Am. J. 2016, 80, 1167-1180. [CrossRef]

21. Fenton, O.; Vero, S.; Schulte, R.P.O.; O'Sullivan, L.; Bondi, G.; Creamer, R.E. Application of Dexter's soil physical quality index: An Irish case study. Ir. J. Agric. Food Res. 2017, 56, 45-53. [CrossRef]

22. Assouline, S.; Or, D. The concept of field capacity revisited: Defining intrinsic static and dynamic criteria for soil internal drainage dynamics. Water Resour. Res. 2014, 50, 4787-4802. [CrossRef]

23. Han, H.; Giménez, D.; Lilly, A. Textural averages of saturated soil hydraulic conductivity predicted from water retention data. Geoderma 2008, 146, 121-128. [CrossRef]

24. Soil Survey Staff. Soil Taxonomy: A Basic System of Soil Classification for Making and Interpreting Soil Surveys, 2nd ed.; USDA-Soil Conservation Service, Agricultural Handbook \#436; U.S. Government Printing Office: Washington, DC, USA, 1999; p. 869.

25. Peel, M.C.; Finlayson, B.L.; McMahon, T.A. Updated world map of the Köppen-Geiger climate classification. Hydrol. Earth Syst. Sci. 2007, 11, 1633-1644. [CrossRef]

26. Gómez, J.A.; Campos, M.; Guzmán, G.; Castillo-Llanque, F.; Vanwalleghem, T.; Lora, A.; Giráldez, J.V. Soil erosion control, plant diversity, and arthropod communities under heterogeneous cover crops in an olive orchard. Environ. Sci. Pollut. Res. 2018, 25,987-989. [CrossRef]

27. Pastor, M.; Castro, J.; Vega, V.; Humanes, M. Sistemas de Manejo del Suelo en el Cultivo del Olivo.: El Cultivo del Olivo, 3rd ed.; Barranco, D., Fernández-Escobar, R., Rallo, L., Eds.; Mundiprensa: Madrid, Spain, 1999. (In Spanish)

28. Guzmán, G. Evaluación de la Influencia del Manejo del Suelo Sobre su Calidad en dos Ensayos de Olivar; Agr. Eng. Diploma Diss. Dept. of Agronomy, Univ. of Cordoba: Córdoba, Spain, 2007. (In Spanish)

29. Raats, P.A.C. Developments in soil-water physics since the mid. 960s. Geoderma 2001, 100, 355-387. [CrossRef]

30. Heinen, M.; Bakker, G. Implications and application of the Raars superclass of soil equations. Vadose Zone J. 2016, 15. [CrossRef]

31. Santos, G.G.; da Silva, E.M.; Marchão, R.L.; da Silveira, P.M.; Bruand, A.; Becquer, T. Analysis of physical quality of soil using the water retention curve: Validity of the S-index. Comptes Rend. Geosci. 2011, 343, 295-301. [CrossRef]

32. Brutsaert, W. Probability laws for pore-size distributions. Soil Sci. 1966, 101, 85-92. [CrossRef]

33. Kosugi, K. Three-parameter lognormal distribution model for soil water retention. Water Resour. Res. 1994, 30, 891-901. [CrossRef]

34. Bury, K. Statistical Distributions in Engineering; Cambridge Univ. Press: Cambridge, UK, 1999.

35. Whittaker, E.T.; Watson, G.N. A Course of Modern Analysis, 4th ed.; Cambridge Univ. Press: Cambridge, UK, 1996.

36. Rosenbrock, H.H. An automatic method for finding the greatest or least value of a function. Comp. J. 1960, 3 , 175-184. [CrossRef] 
37. Vanderlinden, K.; Pachepsky, Y.A.; Pedrera-Parrilla, A.; Martínez, G.; Espejo-Pérez, A.J.; Perea, F.; Giráldez, J.V. Water retention and preferential states of soil moisture in a cultivated vertisol. Soil Sci. Soc. Am. J. 2017, 81, 1-9. [CrossRef]

38. Reynolds, W.D.; Drury, C.F.; Tan, C.S.; Fox, C.A.; Yang, X.M. Use of indicators and pore volume-function characteristics to quantify soil physical quality. Geoderma 2009, 152, 252-263. [CrossRef] 